\title{
PALESTRA:
}

\section{Questões sobre música, cultura e educação}

Luciano Py de Oliveira

Cada vez mais o tema música na cultura tem sido discutido, não só em ambientes acadêmicos e especializados, mas na nossa sociedade em geral.

Talvez isso seja devido ao incrível aumento na velocidade e na abrangência das comunicações, intensificando o contato entre as diferentes culturas do mundo. Desse modo, muitas delas estão se transformando, devido a esse contato, principalmente com a cultura ocidental. Fenômenos como a ocidentalização e a modernização transformam estilos musicais, criando uma tendência a homogenização desses estilos (Nettl 1983, 353-354).

Especificamente nos dias atuais, pode se perceber estes fenômenos através de um exemplo bastante popular. Já está amplamente difundido, principalmente no contexto cultural das bandas pop, o termo World Music - estilo que representaria a "música do mundo", mesclando-se vários estilos, principalmente os de tradição oral, aos ritmos pop das cidades, como o Funk, o Rock e o Blues. Desse modo, 
muitas músicas tradicionais (no caso brasileiro, o samba e o forró são alguns exemplos), hoje estão se transformando, pois passam a ser parte desta World Music, difundidas pelos mais sofisticados meios de comunicação de massa (para uma crítica da cultura dos meios de comunicação em massa, ver Stam 1988).

Entretanto, a World Music não representa, verdadeiramente, um estilo musical global, mas sim, um produto da moderna sociedade capitalista. Produto este extremamente comercializável e lucrativo, pois pode acomodar qualquer estilo tradicional num formato pop, ou seja, vozes cantando em dialeto, amplificadas por microfones e amplificadores; modernos instrumentos musicais da cultura ocidental, como guitarras elétricas, teclados sintetizadores, bateria, mesclados aos instrumentos tradicionais como atabaques, djembês, calimbas e berimbaus, por exemplo, no caso do African Pop. Muitas vezes, os artistas locais não passam de "coadjuvantes" ao lado de grandes nomes do pop internacional que resolveram aderir ao movimento World Music (ver Lühning 1991, 121).

Todos esses fenômenos estão se relacionando a um elemento característico do ser humano. Cultura envolve todo o conhecimento humano, passível de aprendizado, e que diferencia o homem de outros animais. 0 seu relacionamento com a natureza é diferenciado por que o homem tem "a seu dispor duas notáveis propriedades: a possibilidade da 
comunicação oral e a capacidade de fabricar instrumentos, capazes de tornar mais eficiente o seu aparato biológico" (Laraia 1996, 28-29). Em outras palavras, "o homem é o único ser possuidor de cultura" $(1996,29)$. Todo o conhecimento de um determinado grupo humano para lidar com a natureza; para relacionar indivíduos deste mesmo grupo, que se identificam através de uma linguagem; para estabelecer normas de convívio social e de sobrevivência; para buscar um entendimento do mundo enquanto algo sagrado; para recriar e experimentar 0 mundo na arte; todo este conhecimento é considerado como cultura.

Depois dessa reflexão, pode se pensar a música como algo próprio da cultura, uma parte dela. E como ela é definida na nossa cultura, dita ocidental? Um primeiro conceito de música pode ser obtido na mais básica bibliografia disponível, o dicionário da língua portuguesa.

0 verbete é descrito, inicialmente, como uma arte onde seu material básico é o som. Num segundo momento, é também a forma e a maneira de se registrar e reproduzir essa arte. Por exemplo: "1. Arte de combinar tonalidades e sons de maneira agradável ao ouvido. 2 . Composição musical. 3. O modo de executar uma peça musical [...] . 4. Papéis ou livros em que se acha escrita uma peça ou composição musical" (Luft 1984, 389). Então, música, na nossa cultura, é uma arte, tem uma forma e pode ser registrada através de símbolos, semelhantes à escrita. 
O antropólogo Bruno Nettl também levanta estas questões. As definições de música em dicionários da língua inglesa não são diferentes da definição acima citada. Acrescentando, observa que os dicionários especializados em música procuram uma definição mais neutra, sendo a música constituída de sons, causadora de impacto emocional, com status de arte. Ou ainda, música pode ser elevada ao status de ciência ao combinar sons de maneira lógica e expressiva, ligando música à comunicação e à linguagem: música é discutida em termos de tons (para o Ocidente, os elementos básicos de construção da música), beleza e inteligibilidade (música como arte e ciência), e expressividade (música como comunicação) (Nettl 1983, 16).

Entretanto, ao se confrontar essas definições com o que as pessoas pensam sobre música, muitas vão discordar, pois relacionarão música com outros aspectos da vida humana. $\mathrm{E}$, mesmo aceitando o conceito de 'arte e ciência dos sons combinados', muitas obras musicais, consideradas geniais pelos críticos especializados de música, poderão não preencher universalmente o conceito de música como algo 'agradável ao ouvido'.

Ou seja, a definição obtida nos dicionários não é a mais adequada para definir música de uma maneira mais ampla. Nem todas as músicas são, realmente, apenas para agradar ao ouvido. Nem todos os músicos precisam "ler" música para, efetivamente, realizá-la. De fato, isso é explicável numa sociedade com diferentes 
classes econômicas, onde existirão diferentes culturas dentro dela própria. E essa música registrada através de símbolos gráficos, com uma estrutura formal de execução e aprendizado, é mais característica de uma elite e por isso pode ser chamada de música "erudita": aquela produzida pelos grandes compositores, na maioria europeus, executada em espaços próprios, como teatros.

Em contrapartida, a música dita "folclórica", por exemplo, é aquela produzida pelo povo, num sentido mais genérico, a população do meio rural.

Em outras palavras, a música dos camponeses, que é passada de geração em geração, e está ligada às danças, festividades e celebrações, muitas vezes de caráter religioso e sagrado. Com certeza, essa música não está preocupada somente - se é que está - em agradar ou não aos ouvidos. É a chamada música de tradição oral, e tem sido tomada como fonte de inspiração para muitos compositores "eruditos".

Mas essa música tradicional não deveria ser chamada de música popular? De fato, a chamada música folclórica está ligada às camadas populares, mas a definição de música popular está mais voltada ao conceito de cultura popular, mais precisamente, dos centros urbanos e industrializados.

Então, transpõe-se o conceito de música como uma 'arte para agradar os ouvidos', no caso preenchendo uma função de apreciação 
estética, para compreender música como elemento de ligação entre grupos, como apreciação corporal, como elemento de rituais religiosos e sagrados, enfim: percebe-se que a música possui mais do que uma função para um grupo humano, uma sociedade. Para um estudo mais aprofundado do papel da música para as sociedades humanas, torna-se necessário o estudo música nas várias culturas do mundo, e é nesse momento que a musicologia, ciência que estuda a música nos seus mais amplos aspectos, vai de encontro à disciplina que estuda o homem nos seus mais amplos aspectos, a antropologia (sobre música na cultura ver Nettl 1983, 131-161).

Desse encontro, pode se dizer que surgiu uma disciplina que estuda a música de uma maneira mais abrangente, levando em consideração conceitos oriundos de toda e qualquer cultura: a etnomusicologia. É claro que esta definição é bastante didática, pois definir uma disciplina depende de muitas épocas e vertentes (Lühning 1991). Uma definição mais geral poderia ser o estudo da "música viva, atual, fora dos limites da música erudita dos centros urbanos da Europa" (Lühning 1991, 105).

A palavra etnomusicologia pode soar, às vezes, como nova para muitas pessoas, mas, no meio acadêmico, a disciplina tem mais de um século de existência. Ela surgiu como uma das ramificações da musicologia, que se subdivide em histórica, sistemática e a comparativa, esta última predecessora da etnomusicologia. 
Ela surgiu no final do século XIX, juntamente com outras ciências humanas, como a psicologia, a sociologia e a antropologia (ver Krader 1980 e Bastos 1995). Nesse momento, chamava-se musicologia comparada ou comparativa - ciência que buscava a evolução da música através do estudo comparativo entre estilos musicais oriundos de culturas exóticas. $\mathrm{Na}$ época, os cientistas buscavam seus resultados com base em experimentos e testes de laboratório.

Estes eram somados aos dados relacionados a outras culturas do mundo, obtidos através dos relatos de viajantes e missionários. Era a chamada "pesquisa de gabinete".

Com o aumento da consciência crítica nas ciências humanas, em especial na antropologia cultural, a orientação evolucionista da disciplina foi sendo abandonada em favor de uma orientação menos etnocêntrica, valorizando as culturas como elas são de fato, relativizando-as e não as comparando (ver Lühning 1991 e Reily 1990, 22-28). Essa transformação significativa no pensamento acadêmico gerou o chamado relativismo cultural, em oposição a outras correntes de pensamento, como o determinismo biológico e o determinismo geográfico (Laraia 1996, 17-24). Para isso, era necessário que o pesquisador fosse, 'em pessoa', observar as ditas culturas exóticas, pois os depoimentos obtidos indiretamente eram extremamente preconceituosos, ou mesmo incompletos para o 
estudo mais profundo de tais culturas. Surge, então, a chamada pesquisa de campo. Essas mudanças alcançaram a musicologia comparativa, a ponto de se repensar o seu próprio nome. Nos anos 50, o musicólogo Jaap Kunst sugeriu o termo etno-musicologia, sugestão essa que, logo, foi aceita; apenas o hífen foi retirado (ver Bastos 1995, 14-17).

A pesquisa de campo vem a ser, desse modo, a principal ferramenta da etnomusicologia. Provavelmente a primeira pesquisa de campo realizada na antropologia foi a de Malinowski (1984, $3^{\text {a }}$ ed.), mas até hoje as dificuldades que 0 célebre pesquisador enfrentou persistem: o contato com outra cultura e seus diferentes valores, que geralmente entram em "choque" com os do pesquisador. Com certeza, este contato cria certas dificuldades; como relata o antropólogo Anthony Seeger (1980, 25-26), "toda pesquisa de campo é, até certo ponto, uma violação da sociedade que é estudada, pois os antropólogos, às vezes, têm de fazer perguntas difíceis e desagradáveis".

No campo, antropólogos e etnomusicólogos precisam ser, num certo sentido, amparados por equipamentos de auxílio à pesquisa de campo, como de registro sonoro e visual. No caso da etnomusicologia, a invenção do primeiro aparelho de registro sonoro, o fonógrafo, por Thomas Edison, foi determinante. A possibilidade de se registrar sons para depois ouvir gerou a necessidade em se entender 
melhor esses sons, principalmente se eles são produzidos por seres humanos. Uma maneira é descrever visualmente essas novas músicas: são as chamadas transcrições, que constituem uma ferramenta básica da etnomusicologia. Associada a pesquisa de campo, as transcrições musicais servirão de base para, de acordo com o interesse do pesquisador, uma análise do material coletado.

Sendo a etnomusicologia esta ciência que estuda a música na cultura, ela irá ter interesse em todas as áreas da cultura onde a música pode estar inserida. A educação, ou seja, o conjunto de processos de transmissão do conhecimento, é um dos elementos mais importantes para a cultura; o modo como um grupo humano ensina música pode ser de extremo valor para entender a cultura desse grupo. Crianças podem, por exemplo, aprender os elementos e valores mais importantes de sua sociedade através da experiência musical (Nettl 1983, 323).

O exemplo da nossa própria sociedade mostra que a prática musical, ou seja, a execução através do canto e/ou de instrumentos não somente é extremamente valorizada, como também exigida. Uma boa execução de uma peça musical está relacionada à exatidão desta execução. Três aspectos podem ser levantados: 1. A repetição de material didático previamente padronizado, como exercícios técnicos, escalas e estudos; 2. A memorização dos elementos musicais que abstratamente estão colocados nas 
partituras; 3. O estudo da música em partes, o que indica a pressão exercida pela valorização extrema da técnica de execução; em outras palavras, a idéia de se fazer música como algo muito difícil (Nettl 1983, 328). Essa exigência na busca pela perfeição técnica é a realidade dos músicos não só da sociedade ocidental, mas de muitas outras culturas.

Por outro lado, a utilização da música como disciplina auxiliar na educação em geral, especialmente infantil, mostra um outro lado da música na nossa sociedade. Os educadores especializados no ensino e aprendizagem da música vêm demonstrando, cada vez mais, como a música pode, como já foi dito, ajudar a repassar os valores mais importantes da cultura. Tendo esse papel tão importante na educação, torna-se necessário para os educadores uma visão de música mais ampla, mesmo da sua própria música e sua própria sociedade.

Definir música, mesmo dentro da nossa cultura, já é uma tarefa difícil. No caso brasileiro, temos muitas culturas dentro do nosso próprio país; cabe ao educador entrar, cada vez mais, em contato com estas "culturas internas"; o próprio contato com os alunos levará o educador a conhecer esta realidade multicultural.

0 mundo em que vivemos, hoje, praticamente nos obriga a entrar em contato com muitas informações ao mesmo tempo, e principalmente sobre outras culturas. Há uma 
tendência, nesse momento, em se "misturar" essas culturas, devido ao intenso contato, e parece que estamos caminhando para "uma só cultura". Creio ser isso impossível, na prática, pois a diversidade cultural, ou seja, essa capacidade humana de viver nesse mundo e lidar com ele de infinitas maneiras, é uma das características vitais do ser humano.

No caso específico da educação musical, reconhecer essa diversidade é preciso. Uma forma é utilizar a etnomusicologia, por exemplo, na prática de ensino: desde a produção do som até a construção de instrumentos musicais e a composição musical. De uma maneira mais ampla, mas ao mesmo tempo convivendo com as múltiplas diferenças e possibilidades que as culturas do mundo têm para oferecer.

\section{Referências bibliográficas}

BASTOS, Rafael. Esboço de uma teoria da música: Para além de uma antropologia sem música e de uma musicologia sem homem. Anuário Antropológico /93. Rio de Janeiro: Tempo Brasileiro, 1995.

KRADER, Barbara. Ethnomusicology. In New Grove's Dictionary of Music and Musicians. Stanley Sadie, ed. London: Macmillan Publishers Limited. 20 v., v. 6, 1980, pp. 275-282. 
LARAIA, Roque de Barros. Cultura: Um conceito antropológico. $11^{\mathrm{a}}$ ed. Rio de Janeiro: Jorge Zahar, 1996.

LUFT, Celso Pedro. Pequeno dicionário da língua portuguesa. São Paulo: Scipione, 1984.

LÜHNING, Angela E. Métodos de trabalho de campo na etnomusicologia: Reflexões em volta de experiências pessoais. Revista de ciências sociais XXII (1/2), 1991, pp.105-126.

MALINOWSKI, Bronislaw Kasper. Argonautas do Pacífico Ocidental: Um relato do empreendimento e da aventura dos nativos nos arquipélagos da Nova Guiné Melanésia. $3^{\mathrm{a}}$ ed. Anton P. Carr e Lígia Aparecida C. Mendonça, trads. Eunice Ribeiro Durham, rev. São Paulo: Abril Cultural, 1984.

MERRIAM, Alam P. The Anthropolgy of Music. Evanston, Ill.: Nortwestern University Press, 1964.

NETTL, Bruno. The Study of Ethnomusicology:

Twenty-Nine Issues and Concepts. Urbana:

University of Illinois Press, 1983.

REILY, Suzel Ana. Manifestações populares: Do 'aproveitamento a reapropriação'. In Suzel A. Reily e Sheila M. Doula, orgs. Do Folclore à Cultura Popular. São Paulo: USP, 1990, pp. 1-31.

SEEGER, Anthony. Pesquisa de campo: uma criança no mundo. In Os índios e nós. Rio de Janeiro: Campus, 1980, pp. 25-40. 
STAM, Robert. Mikhail Bakhtin e a crítica cultural de esquerda. In 0 mal estar no pósmodernismo: Teoria, prática. E. Ann Kaplan, org. Rio de Janeiro: Zahar, 1988. 